\title{
Laparoscopic Versus Open Appendectomy for Appendicitis in Elderly Patients
}

\author{
Hyun Nam Baek, Yong Hwan Jung, Yong Hee Hwang \\ Department of Surgery, Sahmyook Medical Center, Seoul, Korea
}

Purpose: The appendectomy is the most common emergent surgical procedure in elderly patients. The increasing number of elderly persons has been accompanied by an increase in the number of cases of acute appendicitis in the elderly. In order to understand the clinical significance of a laparoscopic appendectomy for elderly patients with appendicitis, we investigated the results of a laparoscopic appendectomy for treating patients over 60 years of age with appendicitis and compared them with the results for an open technique.

Methods: We studied retrospectively patients over 60 years of age who underwent an appendectomy with either a laparoscopic (LA) or open (OA) technique for appendicitis between July 2007 and December 2009. There were 30 patients in the LA group and 47 patients in the OA group. The demographic data, operative time, length of the hospital stay, bowel movement, pain control, cost, complications and pre-existing disease were assessed.

Results: There were no significant differences between the LA and the OA groups with respect to pre-existing diseases, gender, age, American Society of Anesthesiologists (ASA) score and the number of cases of complicated appendicitis, operative time, length of hospital stay, and times of analgesics use. However, the proportion of early gas out (within POD \#2) was significantly greater in the LA group $(80 \%$ vs. $57 \%, \mathrm{P}<0.05)$, and postoperative complications were significantly lower in the LA group $(7 \%$ vs. $32 \%, \mathrm{P}<0.01)$. The costs for the two groups were not significantly different.

Conclusion: A laparoscopic appendectomy is a safe and effective procedure in elderly patients and is not associated with any increase in morbidity. It can be recommended for routine use in treating elderly patients with appendicitis.

\section{Keywords: Laparoscopy appendectomy; Appendicitis; Aged}

\section{INTRODUCTION}

Appendicitis is one of the most common diseases provoking acute abdominal pain needing surgical treatment, and its incidence rate in the elderly is expected to increase more and more with the growing elderly population due longer life expectancy resulting from socioeconomic growth and advances in medicine. Appendicitis patients aged over 60 years are known to account for around $10 \%$ of the total appendicitis patients $[1,2]$. The disease in the elderly is

Received: July 25, 2011 Accepted: October 20, 2011

Correspondence to: Yong Hee Hwang, M.D.

Department of Sugery, Sahmyook Medical Center, 29-1 Hwigyeong 2-dong,

Dongdaemun-gu, Seoul 130-711, Korea

Tel: +82-2-2210-3563, Fax: +82-2-2212-2673

E-mail: hwangyon@hotmail.com

(c) 2011 The Korean Society of Coloproctology

This is an open-access article distributed under the terms of the Creative Commons Attribution NonCommercial License (http://creativecommons.org/licenses/by-nc/3.0) which permits unrestricted noncommercial use, distribution, and reproduction in any medium, provided the original work is properly cited. associated with perforation at diagnosis in many cases because of the rapid spread of inflammation caused by their weakened antiinflammatory function due to the reduced peritoneum and decreased adipose tissues [3], and their postoperative complication rate and mortality rate are higher.

Although the basic surgical technique for acute appendicitis is open surgery, a laparoscopic appendectomy has been applied to both children and adults since it was introduced by Semm [4] in 1983, and as laparoscopic surgery for other intraperitoneal diseases has increased. it has been substituted for an open appendectomy in all age groups. As a laparoscopic appendectomy for elderly patients with appendicitis has also been conducted more, the authors compared laparoscopic and open appendectomies to determine their suitability and safety in the elderly.

\section{METHODS}

This is a retrospective study conducted with 77 (13.1\%) patients aged over 60 years who had histologically confirmed appendicitis 
from among 585 patients undergoing an appendectomy after having been diagnosed as having acute appendicitis during the two years and six months from July 2007 to December 2009. The subjects were divided into the open and the laparoscopy groups for comparison.

All patients in this study took abdominal ultrasound or computerized tomography (CT) before the surgery, and perforating appendicitis was defined as histologically necrotizing or perforating change or the association of abscess around the appendix. Patients or their guardians chose between a laparoscopic and an open appendectomy after having received explanations of both of them, and it was also explained that laparoscopic surgery could be converted to open surgery. Out of the total 77 cases, the surgery in 74 cases (96\%) was performed within 24 hours after the visit to the hospital, and 33 (43\%) and 44 (57\%) surgeries were done by third- or higher-year surgical residents under the supervision of surgeons and by four surgeons, respectively.

The open appendectomy (OA) was performed with a common technique following the McBurney or paramedian incision on the right lower quadrant. The laparoscopic appendectomy (LA) utilized the three-port method, and a 5-mm trocar was inserted into the suprapubic area and the left lower quadrant after the insertion of a 12-mm trocar directly under the umbilicus. The abdominal pressure was maintained to be less than $12 \mathrm{mmHg}$, and after the dissection of the appendix, its mesentery was treated with electrocautery and, if necessary, a 5-mm Endoclip (Ethicon Endo-Surgery Inc., Chicinnati, OH, USA) or hem-o-lok (Weck Closure Systems, Research Triangle Park, NC, USA) in the initial stage. In the final stage, an ultrasonic cutting device (Sonosurg, Olympus, Tokyo, Japan) was mainly used. The appendix base was ligated two times by using an Endoloop (Ethicon, Sommerville, NJ, USA); then, the bleeding was stopped. The inflammatory exudates in the abdominal cavity were aspirated and washed, and the dissected appendix was put into a vinyl bag (Lap-bag, Meditech Inframed, Sejong Medical Co., Paju, Korea) for an isolated organ and was removed through the umbilicus into which the $12-\mathrm{mm}$ trocar had been inserted. The drainage tube used in this study was a Jackson Pratt tube and was inserted in 27 cases (57\%) of the open group and in 19 cases (63\%) of the laparoscopy groups, mainly through the right abdominal wall and the suprapubic area, respectively. For perforation, drainage tube was inserted in all cases; otherwise, a catheter was optionally inserted depending on the pattern of remaining inflammatory tissues or exudates.

As antibiotics, second-generation cephalosporin was administered simultaneously with the diagnosis of appendicitis, and in cases of perforating appendicitis, aminoglycoside and metronidazole were added. They were taken until the white blood cell count was normalized, and there was no fever. If the increased white blood cell count or fever continued, abdominal CT was conducted to look for an abscess. If an abscess was observed, it was drained by inserting an ultrasound-guided percutaneous drainage tube.

For the comparative analysis of the two groups, American Soci- ety of Anesthesiologists (ASA) score, the operation time, the types of underlying diseases, the postoperative length of hospital stay, the time to passing gas and taking fluid diet, the frequency of the use of analgesics before passing gas, the frequency of histological perforating appendicitis, complications, and medical costs were analyzed using the student t-test and the chi-square test. The analysis tool pack Microsoft Excel 97, 4.00.950 (Korean Microsoft Co., Seoul, Korea) was used, and a P-value of less than 0.05 was considered to be statistically significant.

\section{RESULTS}

Among the total 77 elderly patients, 47 and 30 underwent open and laparoscopic appendectomies, respectively. The OA group consisted of 22 males and 25 females, and their mean age was $69.0 \pm$ 1.2 years. The LA group included 13 males and 17 females, and their mean age was $67.4 \pm 1.3$ years. There was no statistically significant difference between the two groups. The ASA scores were $1.7 \pm 0.7$ and $1.6 \pm 0.6$ in the OA and the LA groups, respectively, and the difference was not significant. The rates of perforating appendicitis in the two groups also did not show any significant difference, being $47 \%$ and $43 \%$, respectively (Table 1). When underlying diseases at diagnosis of appendicitis were examined, hypertension, diabetes, stroke, aneurysm, lung cancer and chronic hepatitis were found, but the difference between the two groups was not significant (Table 2). The mean operation times of the two groups were similar, being $65.3 \pm 26.3$ and $63.3 \pm 30.6$ minutes in

Table 1. Comparison of an OA and a LA for appendicitis in elderly patients

\begin{tabular}{lccc}
\hline & OA $(\mathrm{n}=47)$ & LA $(\mathrm{n}=30)$ & P-value \\
\hline Age (yr) & $69.0 \pm 1.2$ & $67.4 \pm 1.3$ & NS \\
Sex (M:F) & $22: 25$ & $13: 17$ & NS \\
ASA score & $1.7 \pm 0.7$ & $1.6 \pm 0.6$ & NS \\
No. of perforated & & & \\
$\quad$ Appendices & $22(47)$ & $13(43)$ & NS \\
Operative time (min) & $65.3 \pm 26.3$ & $63.3 \pm 30.6$ & NS \\
Length of hospital stay (day) & $9.0 \pm 5.8$ & $7.4 \pm 3.1$ & NS \\
Gas out $\leq 2$ (\#POD) & $27(57)$ & $24(80)$ & 0.041 \\
Time to liquid diet (\#POD) & $3.5 \pm 1.1$ & $3.2 \pm 0.9$ & NS \\
Analgesics use (time) & $1.2 \pm 1.4$ & $0.8 \pm 1.1$ & NS \\
Pathologic status & & & \\
$\quad$ Exudative & 9 & 8 & NS \\
Suppurative & 16 & 9 & NS \\
Gangrenous & 7 & 5 & NS \\
Perforated & 15 & 8 & NS \\
\hline
\end{tabular}

Values are presented as number (\%) or mean \pm SD.

OA, open appendectomy; LA, laparoscopic appendectomy; NS, not significant; POD, postoperative day; ASA, American Society of Anesthesiologists. 
Table 2. Comparison of pre-existing diseases or comorbid diseases

\begin{tabular}{lccc}
\hline & OA $(\mathrm{n}=47)$ & LA $(\mathrm{n}=30)$ & P-value \\
\hline Hypertension & $16(34)$ & $10(33)$ & NS \\
Diabetes mellitus & $10(21)$ & $2(7)$ & NS \\
Cerebrovascular accident & $3(6)$ & $2(7)$ & NS \\
Aortic aneurysm & $1(2)$ & 0 & NS \\
Lung cancer & $1(2)$ & 0 & NS \\
Hepatitis C & 0 & $1(3)$ & NS \\
\hline
\end{tabular}

Values are presented as number (\%).

OA, open appendectomy; LA, laparoscopic appendectomy; NS, not significant.

the open and the laparoscopy groups, respectively, and the mean length of hospital stay was shorter in the LA group than in the OA group, being $7.4 \pm 3.1$ and $9.0 \pm 5.8$ days, respectively, but theses differences were not statistically significant.

Passing gas early within the postoperative second day was found in $27(57 \%)$ cases of the open group and $24(80 \%)$ cases of the LA group, so the rate of the LA group was significantly higher $(\mathrm{P}<$ $0.05)$, but the time of beginning a fluid diet after the surgery was not significantly different, being $3.5 \pm 1.1$ and $3.2 \pm 0.9$ days in the two groups, respectively. The frequency of postoperative pain control before passing gas was lower in the LA group than in the OA group, being $0.8 \pm 1.1$ and $1.2 \pm 1.4$ times on average, respectively, but the difference showed no statistical significance. The frequency of postoperative complications was significantly lower in the LA group as they were observed in $15(32 \%)$ cases of the OA group and $2(7 \%)$ cases of the laparoscopy group $(\mathrm{P}=0.009)$. In particular, postoperative wound infection was found in $9(19 \%)$ cases of the open group and in 1 (3\%) cases of the LA group, so the difference between the two groups was statistically significant $(\mathrm{P}=0.044)$. Postoperative atelectasis, pneumonia, intestinal ileus and intraabdominal abscess did not show any statistically significant difference between the two groups. Postoperative intraabdominal abscess was observed in one case of the OA group and was treated with percutaneous drainage (Table 3 ).

In both groups, there was no death after the surgery. Two patients (4.2\%) undergoing an open appendectomy were hospitalized again due to mild intestinal ileus during the follow-up period after the discharge, but they recovered from their symptoms after symptomatic treatments and were discharged. During this study period, the laparoscopic surgery was converted to an open one in two $(6.7 \%)$ cases. The first case was treated with open surgery because of a severe hemorrhage during the dissection following a severe adhesion of perforating appendicitis, and the second one led to open surgery because the tissues could not be dissected easily for the abscess around the appendix with severe adhesion. Both cases occurred during early experience, so the open surgery was conducted to treat the appendicitis as safely as possible.
Table 3. Comparison of postoperative complications

\begin{tabular}{lccc}
\hline & $\mathrm{OA}(\mathrm{n}=47)$ & $\mathrm{LA}(\mathrm{n}=30)$ & P-value \\
\hline Atelectasis & $1(2)$ & $1(3)$ & $\mathrm{NS}$ \\
Pneumonia & $1(2)$ & 0 & $\mathrm{NS}$ \\
Ileus & $3(6)$ & 0 & $\mathrm{NS}$ \\
Wound infection & $9(19)$ & $1(3)$ & 0.044 \\
Intraabdominal abscess & $1(2)$ & 0 & NS \\
& $15(32)$ & $2(7)$ & 0.009 \\
\hline
\end{tabular}

Values are presented as number (\%).

OA, open appendectomy; LA, laparoscopic appendectomy; NS, not significant.

\section{DISCUSSION}

Acute appendicitis is a frequently observed surgical disease needing emergency surgery, and the rate of the elderly patients with acute appendicitis has been reported to range from 8.3\% to $16.4 \%$ in South Korea [5-8]. The increase in the elderly population in a rapidly aging society has been associated with a growing incidence rate of senile appendicitis [9], and this tendency should continue. Although persons over 65 years of age tend to be thought of as elderly, in South Korea persons over 60 years of age are conventionally defined as the elderly, so this study included as elderly those over 60 years of age [5-8].

The appendix of the elderly is shrunk anatomically, its lymphatic tissues are reduced and a luminal stenosis caused by fibrosis is observed. In addition, they are vulnerable to ischemia due to arteriosclerosis and have a high risk of early perforation because of weak anti-inflammatory function of the mesentery [3]. On the contrary, the decreased immunologic function leads to mild fever and to an increase in white blood cell count $[10,11]$. Abdominal myoatrophy declines rebound tenderness, and the change in the nervous system response caused by aging increases the threshold for pain and provokes a change in the detection and the limiting of pain, so the clinical features of the elderly with appendicitis are untypical and mild.

The general advantages of a laparoscopic appendectomy compared to an open one are smaller surgical scar, less postoperative pain, shorter time for recovery of bowel movement, better activities of daily living, nearly no wound infection, and wider field of vision for surgery to facilitate additional diagnosis and treatment in cases of ambiguous diagnosis or other associated diseases [1218]. In this study, the mean operation time was defined as the time from skin incision to the end of skin suture after the removal of the trocar. Unlike the findings of previous studies that a laparoscopic appendectomy took a longer time than open surgery $[19,20]$, the operation time was nearly the same between the two groups in this study, and that was considered to be because the use of an ultrasonic cutting device shortened the time to deal with the mesentery of the appendix and because in cases of appendicitis associated with complications, the laparoscopic surgery could remove the intra- 
peritoneal abscess or inflammatory exudates more rapidly.

When passing gas early within two days after the surgery was compared, the rate of the laparoscopy group was significantly higher $(\mathrm{P}<0.05)$, so gas was passed earlier overall in the laparoscopy group. That was considered to be because the patients undergoing laparoscopic surgery exercised more as the surgery provoked less pain than open surgery [21]. In addition, compared to other studies, the rate of use of analgesics before passing gas was lower, less than one time on average, in the laparoscopy group, but the length of hospital stay was longer $[22,23]$. That was thought to be because the elderly characteristically do not prefer early discharge in South Korea, so they are usually discharged from hospitals after a complete recovery.

For postoperative complications, Kehagias et al. [24] and McKinlay et al. [25] reported that a laparoscopic appendectomy showed a higher incidence rate of postoperative intraperitoneal abscess than an open one, but Canty et al. [26] and Markides et al. [27] reported that even in appendicitis associated with complications, there was no difference in abscess formation and small bowel obstruction between the two surgical techniques.The study found that the rate of total complications was lower in the laparoscopy group, as in other reports $[21,23](\mathrm{P}<0.01)$ and especially the rate of postoperative wound infection was significantly lower in the laparoscopy group than in the open group, being $1(3 \%)$ and $9(19 \%)$ cases, respectively $(\mathrm{P}<0.05)$. That was considered to be because laparoscopic surgery utilized a small incision compared to open surgery using a relatively large incision. This study found no cases of intraabdominal abscess for laparoscopic surgery and that was thought to be due to complete aspiration.

As the incidence of appendicitis in the elderly population is expected to increase more and more with the rapidly growing elderly population and with the increased recognition of a laparoscopic appendectomy by patients, increased interest in postoperative scaring, increasing skill of surgeons and development of devices for laparoscopic surgery, a laparoscopic appendectomy can be considered preferentially compared to an open appendectomy because it produces smaller surgical scar and less postoperative pain and has a shorter time to recovery of bowel movement, better activities of daily living, nearly no wound infection and a wider field of vision for surgery to facilitate additional diagnosis and treatment in cases of ambiguous diagnosis or other associated diseases. In addition, a laparoscopic appendectomy does not lead to a deterioration of underlying diseases, more postoperative complications, or death in elderly patients.

In the elderly patients, the laparoscopic appendectomy showed fewer complications and faster recovery than the open surgery although the operation time, the length of hospital stay and the medical costs were similar. From these results, a laparoscopic appendectomy can be considered preferentially as treatment for appendicitis in elderly patients.

\section{REFERENCES}

1. Addiss DG, Shaffer N, Fowler BS, Tauxe RV. The epidemiology of appendicitis and appendectomy in the United States. Am J Epidemiol 1990;132:910-25.

2. Temple CL, Huchcroft SA, Temple WJ. The natural history of appendicitis in adults: a prospective study. Ann Surg 1995;221:278-81.

3. Gurleyik G, Gurleyik E. Age-related clinical features in older patients with acute appendicitis. Eur J Emerg Med 2003;10:200-3.

4. Semm K. Endoscopic appendectomy. Endoscopy 1983;15:59-64.

5. Lim CY, Ree JK, Jeong YC, Chae KM. A comparative study of the appendicitis in different age groups. J Korean Surg Soc 1988;35: 207-14.

6. Hong SK, Kim HS. Clinical review of the acute appendicitis in patients over the age of 60. J Korean Surg Soc 1993;44:449-55

7. Sim HS, Lee YK, Hwang JY. Acute appendicitis in the aged. J Korean Surg Soc 1998;54:695-700.

8. An SS, Soh YS, Cho IH, Back HM, Lee SY. Clinical analysis of acute appendicitis in the elderly. J Korean Soc Coloproctol 2002; 18:274-80.

9. Scher KS, Coil JA. The continuing challenge of perforating appendicitis. Surg Gynecol Obstet 1980;150:535-8.

10. Owens BJ, Hamit HF. Appendicitis in the elderly. Ann Surg 1978; 187:392-6.

11. Lau WY, Fan ST, Yiu TF, Chu KW, Lee JM. Acute appendicitis in the elderly. Surg Gynecol Obstet 1985;161:157-60.

12. Canty TG Sr, Collins D, Losasso B, Lynch F, Brown C. Laparoscopic appendectomy for simple and perforated appendicitis in children: the procedure of choice? J Pediatr Surg 2000;35:1582-5.

13. Esposito C, Borzi P, Valla JS, Mekki M, Nouri A, Becmeur F, et al. Laparoscopic versus open appendectomy in children: a retrospective comparative study of 2,332 cases. World J Surg 2007;31:750-5.

14. Esposito C, Ascione G, Garipoli V, De Bernardo G, Esposito G. Complications of pediatric laparoscopic surgery. Surg Endosc 1997; 11:655-7.

15. Juricic M, Bossavy JP, Izard P, Cuq P, Vaysse P, Juskiewenski S. Laparoscopic appendicectomy: case reports of vascular injury in 2 children. Eur J Pediatr Surg 1994;4:327-8.

16. Golub R, Siddiqui F, Pohl D. Laparoscopic versus open appendectomy: a metaanalysis. J Am Coll Surg 1998;186:545-53.

17. el Ghoneimi A, Valla JS, Limonne B, Valla V, Montupet P, Chavrier Y, et al. Laparoscopic appendectomy in children: report of 1,379 cases. J Pediatr Surg 1994;29:786-9.

18. Park JB, Sul JY. Laparoscopic appendectomy: a safe primary procedure for complicated appendicitis. J Korean Surg Soc 2007;72: 51-6.

19. Kirshtein B, Perry ZH, Mizrahi S, Lantsberg L. Value of laparoscopic appendectomy in the elderly patient. World J Surg 2009; 33:918-22.

20. Shaikh AR, Sangrasi AK, Shaikh GA. Clinical outcomes of laparoscopic versus open appendectomy. JSLS 2009;13:574-80.

21. Wei B, Qi CL, Chen TF, Zheng ZH, Huang JL, Hu BG, et al. Lapa- 
roscopic versus open appendectomy for acute appendicitis: a metaanalysis. Surg Endosc 2011;25:1199-208.

22. Tuggle KR, Ortega G, Bolorunduro OB, Oyetunji TA, Alexander $\mathrm{R}$, Turner PL, et al. Laparoscopic versus open appendectomy in complicated appendicitis: a review of the NSQIP database. J Surg Res 2010;163:225-8.

23. Olmi S, Magnone S, Bertolini A, Croce E. Laparoscopic versus open appendectomy in acute appendicitis: a randomized prospective study. Surg Endosc 2005;19:1193-5.

24. Kehagias I, Karamanakos SN, Panagiotopoulos S, Panagopoulos K, Kalfarentzos F. Laparoscopic versus open appendectomy: which way to go? World J Gastroenterol 2008;14:4909-14.

25. McKinlay R, Neeleman S, Klein R, Stevens K, Greenfeld J, Ghory $\mathrm{M}$, et al. Intraabdominal abscess following open and laparoscopic appendectomy in the pediatric population. Surg Endosc 2003;17: 730-3.

26. Canty TG Sr, Collins D, Losasso B, Lynch F, Brown C. Laparoscopic appendectomy for simple and perforated appendicitis in children: the procedure of choice? J Pediatr Surg 2000;35:1582-5.

27. Markides G, Subar D, Riyad K. Laparoscopic versus open appendectomy in adults with complicated appendicitis: systematic review and meta-analysis. World J Surg 2010;34:2026-40. 